\title{
A FORMAÇÃO DE PROFESSORES DE CIÊNCIAS E BIOLOGIA E A EDUCAÇÃO AMBIENTAL: DESVELANDO CONCEPÇÕES E PAPÉIS DE LICENCIANDOS DE UMA UNIVERSIDADE PÚBLICA FEDERAL DE PERNAMBUCO
}

\author{
THE TRAINING OF SCIENCE AND BIOLOGY TEACHERS AND THE \\ ENVIRONMENTAL EDUCATION: UNDERSTANDING THE CONCEPTS AND ROLES \\ OF GRADUATING TEACHERS FROM A PUBLIC FEDERAL UNIVERSITY OF \\ PERNAMBUCO
}

\section{LA FORMACIÓN DE PROFESORES DE CIENCIAS Y BIOLOGÍA Y LA EDUCACIÓN AMBIENTAL: DESVELANDO CONCEPCIONES Y PAPELES DE LICENCIANDOS DE UNA UNIVERSIDAD PÚBLICA FEDERAL DE PERNAMBUCO}

\author{
Izabelle Maria Nascimento de Rezende* \\ Anderson da Silva Coutinho ** \\ Monica Lopes Folena Araújo***
}

\begin{abstract}
Resumo: As concepções dos professores sobre meio ambiente podem nortear suas práticas pedagógicas em Educação Ambiental (EA). Por isso, esta pesquisa tem como objetivo analisar as concepções de EA e meio ambiente dos licenciandos em Ciências Biológicas de uma universidade pública federal localizada em Recife - PE e verificar o que os acadêmicos pensam sobre sua formação e papéis como docentes. Utilizou-se como instrumento de pesquisa um questionário dissertativo. O estudo das respostas foi realizado através da análise de conteúdo sob a perspectiva qualitativa e quantitativa. Quinze estudantes definem meio ambiente sob a ótica naturalista, enquanto onze concebem meio ambiente como naturezasistema. Sobre as concepções de EA, nove são conservacionistas, três são sistêmicas-científicas, e quatro são ecoeducativas. Onze licenciandos se consideram aptos para o trabalho com a EA no ensino básico. Dezessete relatam contribuições positivas do ensino de Ciências e Biologia para a prática da EA como futuros docentes. Diante disso, ressaltamos a necessidade de incorporar ao ensino superior uma EA sistêmica, contextualizada e humanizadora. Propiciando, assim, aos futuros professores uma formação cidadã crítica, consciente, responsável e ativa em sua realidade.
\end{abstract}

Palavras-chave: Concepções. Educação ambiental. Meio ambiente. Universitários. Formação de professores.

\footnotetext{
*Mestre em Ensino de Ciências da Universidade Federal Rural de Pernambuco. Email: izabelle_rezende@yahoo. com.br

** Mestre em em Ensino de Ciências da Universidade Federal Rural de Pernambuco. Email: coutinho.anderson@ hotmail.com

***Doutora em Educação pela Universidade Federal de Pernambuco. Email: monicafolena@gmail.com
} 


\begin{abstract}
The concepts of teachers about environment can guide their teaching practices in Environmental Education (EE). Therefore, this research aims to analyze the concepts of EE and environment on Biological Sciences undergraduate students from a Public University located in Recife - PE and check what they think about their training and roles as teachers. A writing questionnaire was used as the instrument of research. The study of the responses was conducted through the content analysis from the perspective of qualitative and quantitative. Fifteen students define environment from the naturalist perspective, while eleven understand it as a nature-environment system. On the concepts of EE, nine are conservationists, three are systemic-scientific and four are eco-educational. Eleven undergraduates consider themselves able to work with EE in basic education; seventeen of them reported positive contributions of Science and Biology teaching for the practice of EE as future teachers. Consequently, we emphasize the need to incorporate to the undergraduate education a systemic, contextualized and humanizing EE, providing for the future teachers a critical, conscious and responsible training as citizens and active in their reality.
\end{abstract}

Keywords: Concepts. Environmental Education. Environment. University and training.

Resumen: Las concepciones de los profesores sobre medio ambiente pueden nortear sus prácticas pedagógicas en Educación Ambiental (EA). Por eso, esta pesquisa tiene como objetivo analizar las concepciones de EA y medio ambiente de los licenciandos en Ciencias Biológicas de una universidad pública federal localizada en Recife - PE y verificar lo que los académicos piensan sobre su formación y papeles como docentes. Se utilizó como instrumento de pesquisa un cuestionario disertativo. El estudio de las respuestas fue realizado a través del análisis de conteudo sob la perspectiva cualitativa y cuantitativa. Quince estudiantes definen medio ambiente sob la óptica naturalista, mientras once conciben medio ambiente como naturaleza-sistema. Sobre las concepciones de EA, nueve son conservacionistas, tres son sistémica-científicas, y cuatro, eco educativas. Once licenciandos se consideran aptos para el trabajo con la EA en la enseñanza básica. Diecisiete relatan contribuciones positivas de la enseñanza de Ciencias y Biología para la práctica de la EA como futuros docentes. Delante de eso, resaltamos la necesidad de incorporar a la enseñanza superior una EA sistémica, contextualizada y humanizadora. Propiciando, así, a los futuros profesores una formación ciudadana crítica, consciente, responsable y activa en su realidad.

Palabras-clave: Concepciones. Educación ambiental. Medio ambiente. Universitarios y formación de profesores.

\section{Introdução}

A universidade desempenha importante papel na sociedade. Como formadora de futuros profissionais, precisa fornecer os instrumentos para uma formação não apenas científica mas social-cidadã de indivíduos questionadores e proativos em suas realidades. A Educação Ambiental (EA) tem despertado o interesse de diferentes setores sociais, inclusive das Instituições de Ensino Superior (IES).

A docência, como ação interventiva e formadora de sujeitos socioambientais, 
representa um importante meio de exercício da EA. Para isso, o estudo crítico de uma EA contextualizada nas licenciaturas é fundamental para que os futuros docentes construam esses conhecimentos de forma problematizadora e com aplicabilidade na realidade do aluno. Assim, o curso de Licenciatura em Ciências Biológicas deve oferecer subsídios para que este trabalho seja feito de maneira a atender às necessidades supracitadas. Entretanto, muitas vezes, a formação pode não atingir estes objetivos. Por isso, a necessidade de refletirmos sobre ela, considerando, principalmente, as concepções e os papéis docentes na abordagem da EA. Estes questionamentos nos fazem identificar necessidades, lacunas e limitações na formação oferecida nas universidades, motivando-nos a buscar instrumentos que sanem estas deficiências ainda na IES.

A transversalidade torna o tema meio ambiente ainda mais indispensável em abordagens cotidianas formais e não formais. Além disso, pensar e debater a respeito do tema possibilita aos docentes e aos discentes a reflexão para posicionamentos e ações conscientes diante das questões ambientais da atualidade. Considerando que as concepções ambientais dos indivíduos estão intrinsecamente relacionadas às suas práticas docentes e pedagógicas adotadas no exercício da docência, acreditamos que esta análise é bastante pertinente em relação à formação acadêmica dos licenciandos para o trabalho com a EA. Assim, o presente trabalho tem como objetivo geral analisar as concepções dos licenciandos do último período de Ciências Biológicas de uma universidade pública federal acerca da Educação Ambiental e meio ambiente. Definimos como objetivos específicos: verificar se os estudantes consideram sua formação sólida o bastante para o trabalho com EA; analisar como os acadêmicos concebem as contribuições do ensino de Ciências e Biologia para o trabalho com a Educação Ambiental.

\section{Concepções de Meio Ambiente}

Reigota (2002), com descrito na tabela 1, descreve três tipos de concepções sobre ambiente. Na primeira, intitulada como naturalista, o indivíduo concebe meio ambiente como natureza e destaca aspectos naturais e conceitos que se confundem com aqueles relacionados à definição de ecossistema. Apesar de incluir aspectos físico-químicos, a fauna e a flora, o ser humano fica com o papel de observador externo, não pertencente a esta "natureza”. A visão globalizante, na categorização proposta pelo autor, concebe meio ambiente numa perspectiva que envolve as relações entre natureza e sociedade, contemplando aspectos naturais, políticos, sociais, econômicos, filosóficos e culturais. A categoria antropocêntrica relaciona o conceito de meio ambiente aos recursos naturais úteis para sobrevivência humana. Desta forma,

Tabela 1 - Concepções ambientais. Modificado de Reigota (2002).

\begin{tabular}{|c|l|}
\hline Concepções & \multicolumn{1}{c|}{ Características } \\
\hline Naturalista & $\begin{array}{l}\text { Meio ambiente voltado apenas a natureza, evidencia aspectos naturais, confundin- } \\
\text { do-se com conceitos ecológicos como de ecossistema. Inclui aspectos físico-quími- } \\
\text { cos, a fauna e a flora, mas exclui o ser humano deste contexto. O ser humano é um } \\
\text { observador externo }\end{array}$ \\
\hline Globalizante & $\begin{array}{l}\text { O meio ambiente é caracterizado como as relações entre a natureza e a sociedade. } \\
\text { Engloba aspectos naturais políticos, sociais, econômicos, filosóficos e culturais. O } \\
\text { ser humano é compreendido como ser social que vive em comunidade. }\end{array}$ \\
\hline
\end{tabular}


Antropocêntricas

O meio ambiente é reconhecido pelos seus recursos naturais, mas são de utilidade para a sobrevivência do homem.

evidencia-se um papel "utilitarista" da natureza, ou seja, deve fornecer ao homem soberanamente meios para que ele viva.

Já a categorização proposta por Sauvé et al. (2000) divide as concepções de ambiente em sete categorias, como ilustra a Tabela 2. A concepção de ambiente como natureza é representada por meio de elementos bucólicos e característicos de uma natureza isolada, como árvores, animais, lagos e florestas. $\mathrm{O}$ ambiente é visto como recurso quando se evidenciam os serviços e recursos oferecidos pela natureza e que são fundamentais à sobrevivência humana, tais como: a água, a energia, a fotossíntese, os alimentos orgânicos, entre outros. Esses recursos devem ser percebidos para serem gestionados a fim de manter a vida humana. Na concepção de meio ambiente como um problema a ser solucionado, são citados exemplos de problemas ambientais, principalmente de ordem antrópica, que devem ser repensados e, posteriormente, solucionados. A concepção de ambiente como sistema integra conceitos relacionados aqueles da ecologia. O indivíduo faz uso em seu discurso de elementos, como os fatores bióticos e abióticos, as relações ecológicas de um ambiente e definições de ecossistemas muitas vezes. Para esse sujeito, esse ambiente (sistema) necessita de compreensão para que sejam realizadas escolhas no âmbito político e ambiental. A concepção de ambiente como meio de vida diz respeito a todos os lugares que nos rodeiam (bairros, cidade, estado, trabalho, escola, entre outros). Devemos conhecer esse meio de vida para organizá-lo da melhor maneira possível. Em relação à concepção de ambiente como biosfera, o sujeito traz em seu discurso uma visão espacial, planetária de ambiente, em que se percebe o planeta Terra como um ambiente global e ressalta-se a existência de uma cidadania planetária, onde os elementos que a compõem vivem juntos por um longo prazo. E, por último, o autor categoriza a concepção de meio ambiente como um projeto comunitário, segundo o qual devemos nos comprometer e nos responsabilizar pela sua transformação e emancipação.

Tabela 2 - Concepções ambientais. Traduzido e modificado de Sauvé et al. (2000).

\begin{tabular}{|l|l|}
\hline \multicolumn{1}{|c|}{ Concepções } & \multicolumn{1}{c|}{ Palavras-chave } \\
\hline Natureza que devemos apreciar e respeitar. & Preservação, árvores, animais, natureza. \\
\hline Recursos que devemos gestionar. & Água, resíduos sólidos, energia, biodiversidade. \\
\hline Problemas que devemos solucionar. & $\begin{array}{l}\text { Contaminação, queimadas, destruição, danos ambien- } \\
\text { tais. }\end{array}$ \\
\hline $\begin{array}{l}\text { Sistema que devemos compreender para as tomadas de } \\
\text { decisão. }\end{array}$ & $\begin{array}{l}\text { Ecossistema, desequilíbrio ecológico, relações ecoló- } \\
\text { gicas. }\end{array}$ \\
\hline Meio de vida que devemos conhecer e organizar. & $\begin{array}{l}\text { Tudo que nos rodeia, "oikos", lugar de trabalho e estu- } \\
\text { dos, vida cotidiana. }\end{array}$ \\
\hline Biosfera em que vivemos juntos em longo prazo. & $\begin{array}{l}\text { Planeta Terra, ambiente global, cidadania planetária, } \\
\text { visão espacial. }\end{array}$ \\
\hline Projeto comunitário com comprometimento. & $\begin{array}{l}\text { Responsabilidade, projeto político, transformações, } \\
\text { emancipação. }\end{array}$ \\
\hline
\end{tabular}




\section{Concepções de Educação Ambiental}

Sauvé (2004) categoriza as concepções de EA em seis tipos, como descrito na Tabela 3: naturalista, conservacionista-resolutiva, sistêmico-científica, moral ou ética, prática e ecoeducatica ou sustentável. A concepção naturalista compreende como objetivo da EA a reformulação das relações do homem com a natureza. Já na concepção conservacionista-resolutiva, esse tipo de educação é visto como um meio de sensibilização para preservar recursos naturais, orientando principalmente para o uso responsável desses recursos. A visão sistêmico-científica concebe a EA como um instrumento para identificar problemas ambientais, causas, efeitos e propor soluções para eles. A concepção moral ou ética da EA envolve princípios e valores sociais individuais e coletivos que devem ser despertados pela EA baseados na ética ambiental. A prática entende que a EA deve promover a ação diante da reflexão dos resultados negativos das problemáticas ambientais. Por fim, a concepção ecoeducativa compreende que a EA deve estar voltada para a "prática" do desenvolvimento sustentável, possibilitando sempre o aprendizado por meio das relações dos indivíduos com o ambiente, numa perspectiva para um desenvolvimento individual, estimulando ações responsáveis no meio em que vivem.

Tabela 3 - Categorias das concepções de Educação Ambiental. Traduzido e modificado de Sauvé (2004).

\begin{tabular}{|l|l|}
\hline \multicolumn{1}{|c|}{ Concepções de EA } & \multicolumn{1}{|c|}{ Objetivos da EA } \\
\hline Naturalista & Reconstruir uma ligação com a natureza. \\
\hline Conservacionista-resolutiva & $\begin{array}{l}\text { Adotar comportamento de conservação. Desenvolver habilidades } \\
\text { relativas à gestão ambiental. }\end{array}$ \\
\hline Sistêmico-científica & $\begin{array}{l}\text { Desenvolver o pensamento sistêmico: análise e síntese para uma visão } \\
\text { global. Compreender as realidades ambientais, tendo em vis- } \\
\text { ta decisões apropriadas. Construir conhecimentos em ciências am- } \\
\text { bientais. Desenvolver habilidades relativas à experiência científica }\end{array}$ \\
\hline Moral ou ética & Desenvolver um sistema ético. \\
\hline Prática & Aprender em, para e pela ação. \\
\hline Ecoeducativa & $\begin{array}{l}\text { Experimentar o meio ambiente para experimentar-se e formar-se em e } \\
\text { pelo meio ambiente. Constituir uma relação mais equilibrada com o mundo. }\end{array}$ \\
\hline
\end{tabular}

\section{Fatores que Podem Influenciar as Concepções Docentes}

Frente ao exposto, indaga-se sobre quais fatores podem influenciar as concepções de meio ambiente e Educação Ambiental dos estudantes de Licenciatura em Ciências Biológicas, sujeitos desta pesquisa. Como nos diz Furtado (2010), as concepções dos docentes são construídas a partir da interação entre a formação pessoal e científica. A formação pessoal constitui-se das crenças, atitudes e valores dos indivíduos. A formação científica envolve os conteúdos e a maneira como se dá essa aprendizagem. 
Diante disso, é importante destacar a relevância de uma formação sólida no âmbito das Ciências Biológicas para construção de conceitos de meio ambiente e de EA. Frisamos a necessidade de compreender meio ambiente não apenas no que se refere à natureza, mas sim reconhecendo também o homem como integrante do meio ambiente, de modo que a EA possa transitar entre os múltiplos saberes que a constituem. Dessa forma, como aponta Sato (2003), a EA deve estar inserida em um contexto diferenciado que traga de forma indissociada o ambiental, o social, o político e o pedagógico.

Assim, questiona-se: quais as contribuições que o ensino de Ciências e Biologia podem acrescentar ao trabalho com a EA?

\section{Contribuições do Ensino de Ciências e Biologia para o Trabalho com a EA}

Os saberes da Biologia acrescentam ao trabalho com a Educação Ambiental conhecimentos fundamentais para integração do homem no ambiente. A Biologia estuda o fenômeno da vida e todos os seus processos organizados e integrados; e compreende que as formas de vida estão sujeitas a transformações, portanto, influenciam e são influenciadas pelo ambiente no tempo e no espaço (BRASIL, 2002, p.219). Os Parâmetros Curriculares Nacionais para o Ensino Médio (Brasil, 2002) incluem como objetivo geral formativo das Ciências da Natureza, como a Biologia, a compreensão da natureza como uma intrincada rede de relações, um todo dinâmico, do qual o homem é parte integrante, com ela interage, dela depende e nela interfere.

Partindo do pressuposto de que o ensino de Ciências deve subsidiar o pensamento interligado, complexo e contextualizado no processo de ensino-aprendizagem, todos os conteúdos abordados nas grandes áreas da Biologia devem estar prioritariamente inseridos e relacionados à realidade do educando. Somando-se a isso, o ensino deve promover uma percepção diferenciada da natureza, do meio ambiente, de maneira a possibilitar ao aluno o estabelecimento de relações dinâmicas de ordem biológica e social com o meio, compreendendo a si mesmo como um ser ambiental, social, político e cultural.

\section{Metodologia}

Esta pesquisa é caracterizada por uma abordagem qualitativa-descritiva, tomando-se como referência o que diz Oliveira (2005, p. 41) ao considerar este tipo de investigação como um processo de reflexão e análise da realidade através do uso de métodos e técnicas. Os dados foram coletados com vinte licenciandos do último período do curso de Ciências Biológicas de uma universidade pública federal localizada no Recife-PE. A pesquisa foi realizada em junho de 2011. O critério utilizado para a seleção dos alunos foi a disponibilidade deles em participar da pesquisa. Para garantir o anonimato dos atores de pesquisa, os alunos foram nomeados de A1 a A20.

Para Oliveira (2007), a escolha dos instrumentos de pesquisa deve estar em consonância com o objeto de estudo. Assim, optamos por utilizar questionários com os estudantes. O referido instrumento foi constituído de questões abertas, pois era nosso interesse que os alunos participantes tivessem liberdade para dar explicações amplas. As respostas foram analisadas através da análise de conteúdo (BARDIN, 1977). 


\section{Resultados e Discussão}

A pesquisa foi realizada com vinte alunos, dezesseis do sexo feminino e quatro do masculino, com idades entre 22 e 47 anos. Apresentamos os resultados organizados nos seguintes tópicos: concepção de meio ambiente e de Educação Ambiental, formação acadêmica para o trabalho com a Educação Ambiental e papéis a serem desempenhados com a EA como professores da Educação Básica.

\section{Concepções de meio ambiente dos licenciandos}

Questionou-se primeiramente sobre a concepção de meio ambiente dos 20 alunos licenciandos de uma universidade pública federal. A1 e A6, segundo a categorização de Sauvé et al. (2000), classificam o meio ambiente como um sistema, visto que em seus discursos interligam natureza e sociedade participantes na Ecologia e no universo como um todo. É notória a visão fragmentada dos elementos envolvidos, limitando sua definição às relações ecológicas envolvidas, negligenciando as questões sociais, culturais, políticas e éticas existentes. Na classificação de Reigota (2003), esses discursos se inserem na visão naturalista, quando citam a natureza e Ecologia e enquadram o ser humano principalmente como observador externo e não como parte integrante e relacionado ao meio. Molin, Pasquali e Valduga (2007) igualmente afirmam que os alunos de Ciências Biológicas possuem uma concepção naturalista de meio ambiente, a qual o retrata como sinônimo de natureza intocada.
As concepções de A4, A5, A7, A11, A12, A13, A14, A17, A18, A19 e A20 podem ser classificadas como natureza e como sistema, conforme Sauvé et al. (2000), porque relatam elementos naturais e os definem como ecossistema, citando as relações ecológicas existentes. Ilustrando essas concepções, A5 concebe meio ambiente como: "espaço físico onde ocorrem relações ecológicas entre os seres vivos e também onde estão envolvidos fatores bióticos e abióticos". De forma semelhante, A20 relata: "o ambiente físico habitado por diversos organismos que interagem entre si e com o ambiente". Segundo a tipologia de Reigota (2002), os discursos dos onze alunos podem ser enquadrados na visão naturalista, corroborando com Bezerra (2008) que obteve resultados semelhantes, nos quais foi observado que todos os estudantes de Biologia questionados relacionaram meio ambiente a fatores bióticos e abióticos. Definições ecológicas e naturalistas acabam muitas vezes negligenciando as questões sociais, culturais e políticas que compõem o meio ambiente. Oliveira; Obara e Rodrigues (2007) dissertam que para muitos professores educar para o meio ambiente diz respeito apenas à preservação da natureza, o que pode acarretar em uma concepção difusa de meio ambiente, marginalizando outras dimensões de trabalho.

O aluno A2 afirma que meio ambiente depende do contexto, como podemos observar na sua fala: "Meio ambiente é o local onde o homem utiliza os recursos para se manter". Nesse discurso, o ambiente é visto como fonte de recurso que o homem deve gerir para sua sobrevivência. Para Reigota (2002), revela-se uma visão antropocêntrica, em que se manifesta a visão utilitária do meio ambiente, do mesmo modo que para Oliveira; Obara e Rodrigues (2007), segundo os quais o aluno considera o homem como o centro de tudo, e a natureza existe para servi-lo. O ser humano 
não é incluído como parte da "natureza", mas soberanamente extrai dela recursos, ou seja, o ambiente deve se adequar ao homem, e não o contrário. Esta visão utilitarista pode acarretar práticas irracionais, desmedidas e extrativistas no meio ambiente, visto que se pressupõe uma percepção equivocada do homem no controle da natureza, dissociando-o dela, em uma espécie de imunização humana de consequências das atitudes insustentáveis.

A15 afirma que meio ambiente é "todo o meio que nos rodeia"; segundo Sauvé et al. (2000) o meio ambiente está nesse relato concebido como um meio de vida, oikos, aquilo que está ao nosso redor. A16 e A3 relatam que meio ambiente envolve a esfera natural (rios, lagos, florestas) e o lugar em que circulamos diariamente. Para Sauvé et al. (2000) o meio ambiente nessa afirmação é visto como natureza e como meio de vida. A concepção naturalista de Reigota (2003) classifica as respostas de A15 e A16. Todavia, A3 inclui os animais e pessoas que pertencem a este lugar, por isso, na classificação proposta por Reigota (2002), se caracteriza simultaneamente ora como naturalista, ora como globalizante. Assim,como descreve Leff (2001, p. 256), faz-se necessário o desenvolvimento de políticas de Educação Ambiental com o propósito de orientar valores e comportamentos socioambientais.

A concepção de A10 relatou uma visão espacial, planetária e global de ambiente, o que Sauvé et al. (2000) denominam de ambiente como biosfera, mesclando o novo e o antigo. A10 afirma: "Meio ambiente é todo o lugar no planeta onde exista vida, das regiões abissais até os limites atmosféricos e que precisam ser preservados em suas características naturais". Há um pensamento cósmico que remete ao planeta Terra e a uma cidadania planetária, como afirma Sato (2003). Essa concepção possui elementos das categorias naturalista e globalizante, proposta por
Reigota (2002), apesar de não explicitar os fatores sociais globais.

A8 não respondeu a esse questionamento, mas usou uma simbologia de um zero cortado transversalmente, o que foi interpretada na análise como não sabendo definir o conceito de meio ambiente. A9 não soube conceituar e justificou dizendo ser complexo definir meio ambiente.

Bezerra (2008) pontua que a visão naturalista de meio ambiente ainda se apresenta impregnada na concepção dos estudantes. Também é verdade que não há um consenso nas definições de meio ambiente, muitas vezes incompletas no que tange o universo multifacetado desta concepção, podendo acarretar numa incompreensão dos objetivos da EA. Entretanto, como propõe Sauvé et al. (2000), devemos considerar as diferentes estratégias para o trabalho da Educação Ambiental de acordo com as múltiplas concepções ambientais.

\section{Concepções de Educação Ambiental dos licenciandos}

O estudo das concepções sobre Educação Ambiental baseou-se na tipologia desenvolvida por Sauvé (2004), que categoriza os modelos de correntes ou de concepção de Educação Ambiental e suas abordagens educativas, classificadas como naturalista, conservacionista/resolutiva, sistêmica/científica, moral ou ética, prática e ecoeducatica ou sustentável.

Quanto às concepções sobre a Educação Ambiental, A1, A2, A3, A5, A9, A10, A14, A15 e A20 destacam o papel educacional da EA na sociedade para contribuição com a preservação e conservação do espaço em que vivemos. Esta afirmação remete à ideia 
de natureza apenas como elemento biológico e ecossistêmico, desconsiderando o homem como "meio ambiente" e por isso também alvo da EA. Segundo Sauvé (2004), essa concepção é denominada conservacionista, sendo a EA um meio de conscientização para preservar recursos naturais. Para A2: "A EA pode sensibilizar, mudar valores e conceitos de meio ambiente, e preservar recursos naturais". A10 considera a EA como: "É a orientação para todos os tipos de indivíduos para preservação dos recursos naturais e qualidade de vida no planeta". Estas afirmativas assemelham-se às encontradas por Bezerra (2008) que ressalta um papel estratégico da EA em escolas e universidades para preservação e conservação do ambiente. Entretanto, esse tipo de EA pode tornar-se, de acordo com Brügger (1999, p.34), uma educação para conservação, mas não para o ambiente. Uma educação conservacionista é aquela que orienta para o uso responsável de recursos, enquanto a educação para o ambiente implica uma intensa mudança de valores, atitudes e visões de mundo.

A concepção de A4, A13 e A18 a EA se caracteriza por uma visão sistêmica/científica. A18 define a EA da seguinte forma: "É a área da Biologia que trata de problemas que atingem ao meio ambiente". Segundo Sauvé (2004), a EA nesta perspectiva visa identificar problemas ambientais, causas, efeitos e soluções, corroborando com os resultados de Oliveira; Obara e Rodrigues (2007), os quais afirmam que os indivíduos precisam sentir a consequência ambiental próxima deles para se mobilizarem contra efeitos negativos e assim assumirem seus papéis cívicos.

A6 diz: "A EA deve promover a conscientização das pessoas perante a degradação causada pelo homem”. Para Sauvé (2004), essa é uma concepção de EA prática que promove a ação diante da reflexão dos resultados negativos das problemáticas ambientais.
Segundo Dias (2003), a EA objetiva sensibilizar e conscientizar as pessoas sobre as questões ambientais. Nesta concepção o professor reflete com o aluno instrumentando-se na EA para sensibilizá-lo e para pensar em ações que minimizem impactos negativos da atividade humana no ambiente.

As concepções de A8, A11, A16 e A17 configuram-se como ecoeducativas. Segundo Sauvé (2004), a EA é o ensino voltado para a "prática" do desenvolvimento sustentável e forma pessoas para seu desenvolvimento individual e ações responsáveis no meio em que vivem. A11 afirma: "A EA deve formar um cidadão ambientalmente consciente, não só no ambiente escolar, mas for dele". Segundo Carvalho (2008), além da EA formal, é importante considerar o amplo conjunto de práticas sociais e educativas não formais.

Quando indagado sobre o conceito de EA, A7 afirma: "É uma maneira de passar tudo que é importante para sociedade". Observamos nessa definição elementos citados na corrente moral ou ética da EA (Sauvè,), que envolve princípios e valores sociais individuais e coletivos que devem ser despertados pela EA baseados na ética ambiental.

Para A12, a EA destina-se à conscientização da população para preservação do meio ambiente. Na classificação de Sauvé (2004), essa concepção assume características conservacionistas e ecoeducativas. Reigota (2002) constatou, em estudo semelhante, a existência de duas visões gerais da EA: a primeira como conscientizadora, despertando a consciência do indivíduo para sustentabilidade, como podemos observar na fala de A12; e a segunda como disciplina específica.

A19 define EA da seguinte forma: "É o conhecimento adquirido para preservação do meio ambiente e das relações humanas para assim compreender a ação humana na 
natureza". Nas tipologias de Sauvé (2004) essa definição é crítico-social-conservacionista.

\section{Formação acadêmica para o trabalho com Educação Ambiental}

Em relação à aptidão para o trabalho com a Educação Ambiental no ensino básico, A1, A2, A4, A6, A12, A14, A15 e A19 relataram que não se sentiam aptos. A2 ressaltou uma necessidade de aprofundamento na área da Educação Ambiental, como também destaca A6 ao se reportar à falta de capacitação no curso de Ciências Biológicas para o trabalho com EA. A14 e A15 reconhecem a necessidade de um maior preparo. Como descreve Fouto (2002), o docente comprometido com seu papel formador de cidadãos busca uma formação profissional holística e substancial. Este posicionamento crítico-reflexivo dos licenciandos evidencia possíveis lacunas na graduação que devem ser analisadas mais detalhadamente para assim serem suprimidas.

Os licenciandos A4, A12 e A19 associam a formação em EA apenas à disciplina Educação Ambiental, A4 e A12 relatam que apenas possuem conhecimentos básicos aprendidos nesta disciplina, enquanto A19 relata que não cursou a optativa. Lamentavelmente, os discursos retratam uma visão fragmentada e meramente disciplinar da EA, em que os estudantes não conseguem inter-relacionar conteúdos vistos ao longo da graduação com teorias, princípios e práticas em EA. Para Tristão (2004), a graduação deveria ter estruturas curriculares mais flexíveis, abertas, dinâmicas, não oferecendo, portanto, disciplinas específicas. Além, percebemos que esses discursos ferem o princípio transversalizador da EA.
Os licenciandos A3, A5, A7, A8, A9, A10, A11, A13, A16, A17 e A18 sentem-se aptos para trabalhar a EA no ensino básico; A8 diz que "os conhecimentos adquiridos durante o curso foram suficientes". A5 considera-se apto e destaca os múltiplos e dinâmicos recursos didáticos atuais para o aprendizado em ambientes formais e não formais de ensino. Sobre os diversos recursos didáticos, Sato (2003) aponta a importância do uso de debates, jogos, dinâmicas e reflexões para o trabalho com EA na escola. A7 se diz seguro para trabalhar com EA no ensino básico, como evidencia a sua fala: "Tudo que foi ensinado e aprendido dentro e fora do campus foi suficiente para me capacitar." Como destaca Carvalho (2008), a Educação Ambiental atua como ponte de aproximação entre os ambientes formais e não formais de ensino. É importante ressaltar que o estudo limitou-se apenas à análise da formação na universidade para o trabalho em EA no ensino básico, sem inferir sobre as vivências externas dos alunos, seja na formação anterior do ensino básico ou até mesmo em vivências de estágios na área de Educação Ambiental.

A20 diz que ao longo do curso se direcionou para outras áreas de seu maior interesse. Essa resposta não nos revela se este aluno se considera apto para o trabalho em Educação Ambiental no ensino básico.

\section{Contribuições do Ensino de Ciências e Biologia para o Trabalho com a EA}

Quando questionados sobre as contribuições do ensino de Ciências e Biologia para as questões ambientais, os estudantes A1, A3, A4, A5, A7, A9, A10, A11, A12, A13, A14, A15, A16, A17, A18, A19 e A20 as consideraram e exemplificaram seus posicionamentos. 
Citaram conteúdos como ecologia, botânica e zoologia como subsídio para sensibilização, conscientização e cidadania ambiental. Corroborando com o que diz Smyth (1995) sobre o papel sensibilizador da EA, A4 afirma: "O ensino pode contribuir através da identificação dos problemas ambientais, causas, consequências e medidas de combate ou minimização, além também de relatar o papel na mudança de hábito dos indivíduos”. Segundo Oliveira; Obara e Rodrigues (2007) esses futuros educadores têm assumido, ao longo do exercício de sua profissão, a responsabilidade de sensibilizar seus alunos ante os problemas ambientais locais.

Entretanto, observamos que apesar de eles pontuarem a Biologia no trabalho com a EA, os conteúdos da área estão restritos à flora, fauna e relações ecológicas. Não conseguiram relacionar as contribuições possíveis de outras áreas da Biologia, como a fisiologia, a histologia, a anatomia, a citologia, a genética e a bioquímica para o trabalho com EA. Para superar visões reducionistas e considerar outros temas relacionados ao ensino de Ciências e Biologia é indispensável a troca de lentes, como aponta Carvalho (2008). No ensino de Fisiologia Humana, por exemplo, por que não discutir as consequências da poluição ambiental no nosso organismo? Por que não relacionar os efeitos mutagênicos da radioatividade em células somáticas e germinativas? Ou mesmo refletir sobre o acúmulo de substâncias tóxicas provenientes do controle de pragas na agricultura, em nossos tecidos? Respostas que se encontram nas próprias sugestões das Orientações Curriculares para o Ensino Médio, ao relacionarem a necessidade de se trabalharem os seguintes temas: saúde, corpo humano, adolescência, sexualidade, desenvolvimento humano, ética e respeito às diferenças, dinâmica de populações, relações sociedade-natureza manejo de recursos naturais e geração de resíduos. Temáticas que explicitam a necessidade de transversalizar a EA nesse cenário.

Corroborando com Sato (2003) e Dias (2004) que recomendam uma perspectiva multidisciplinar e interdisciplinar para o trabalho em EA, A5 ressalta a importância da multidisciplinaridade no trabalho de Ciências e Biologia e a contribuição do ensino para um pensamento crítico sobre a realidade e os problemas ambientais: "É através do conhecimento biológico que se entende as interações e a importância que todos os seres vivos têm na manutenção do equilíbrio ecológico”.

A2 não respondeu a esse questionamento. A8 afirmou apenas que sim, mas não justificou essas contribuições, e A6 diz: "Estas duas disciplinas não auxiliam em nada na nossa formação”.

\section{Considerações Finais}

A pesquisa envolve um levantamento pontual, mas significativo no que tange às concepções de meio ambiente e de EA desses futuros docentes e análise de sua formação e papéis nas questões socioambientais. As concepções dos sujeitos de pesquisa revelam que sua formação pessoal e científica ainda são insuficientes no sentido de transversalizar as áreas da Biologia e outras áreas do conhecimento. As concepções ou definições sobre meio ambiente e Educação Ambiental não devem ser rotuladas como certas ou erradas, apenas se revelam incompletas, sugerindo, inclusive, a revisão das concepções já adquiridas. Entendemos que a docência exige uma reflexão contínua de sua prática interventiva, para que se possa construir, desconstruir e reconstruir valores e atitudes na sociedade. Diante disso, ressaltamos a necessidade de incorporar ao Ensino Superior uma EA 
sistêmica, contextualizada e humanizadora, propiciando, assim, aos futuros professores uma formação cidadã crítica, consciente, responsável e ativa em sua realidade.

\section{Referências}

BARDIN, L. Análise de conteúdo. Lisboa: Edições 70, 1977.

BEZERRA, L. M. Educação ambiental no ensino formal: o caso das licenciaturas da unievangélica. Dissertação de Mestrado, Centro Universitário de Anápolis UniEvangélica, 2008. 136 p.

BRASIL. Parâmetros Curriculares Nacionais para o Ensino Médio. Brasília: MEC/Semtec, 2002.

- Orientações Curriculares para o Ensino Médio. Brasília: MEC/SEB, 2006.

BRÜGGER, P. (1999). Educação ou adestramento ambiental? 2. ed. FlorianópolisSC: letras contemporâneas.

CARVALHO, V. S. de. Educação ambiental e desenvolvimento comunitário. Rio de Janeiro: Wak, 2002.

CARVALHO, I. C. M. A formação do sujeito ecológico. 3. ed. São Paulo: Cortez, 2008.

DIAS, G. F. Educação ambiental: princípios e práticas. 9. ed. São Paulo: Gaia, 2004.

FOUTO, A. R. F. O papel das universidades rumo ao desenvolvimento sustentável: das relações internacionais as práticas locais. 2002. Campus Verde. Disponível em: $<$ http://campus.fct.unl.pt/campusverde/W_ RIA_ARFF.doc.> Acesso em: 10 jun. 2011.

FURTADO, J. A Gestão municipal da educação e o desafio da formação continuada dos professores. Disponível: <http:// juliofurtado.com.br/gestao_municip.pdf $>$. Acesso em: 09 abr. 2012.

LEFF. E. Saber ambiental: sustentabilidade, racionalidade, complexidade, poder. Petrópolis: Vozes, 2001.

MOLIN, R. F.; PASQUALI, E. A.; VALDUGA, A. T. Concepções de meio ambiente formuladas por diversos níveis de ensino. Congresso de Ecologia Do Brasil. Anais... Caxambú, 2007.

OLIVEIRA, A. L.; OBARA, A. T.; RODRIGUES, M. A. Educação ambiental: concepções e práticas de professores de ciências do ensino fundamental. Revista Electrónica de Enseñaza de las Ciencias.[SI], v. 6, n. 3, p. 471-495, 2007. Disponível em: < http: //reec.uvigo.es/volumenes/volumen6/ ART1_Vol6_N3.pdf > Acesso em: 10 jul. 2011.

OLIVEIRA, M. M. Como fazer projetos, relatórios, monografias, dissertações e teses. 3. ed. Rio de Janeiro: Elsevier, 2005.

Como fazer pesquisa qualitativa. Petrópolis, Rio de Janeiro: Vozes, 2007.

REIGOTA, M. Meio ambiente e representação social. 5. ed. São Paulo: Cortez, 2002.

SATO, M. Educação ambiental. São Carlos: RiMa, 2003.

SAUVÉ, L. et al. La educación ambiental: uma realción constructiva enre la escuela y la comunidad. Montreal: Edamaz e Uqám, 2000.

SAUVÉ, L. Una cartografía de corrientes en educacíon ambiental. Montreal: Edamaz e Uqám, 2004. In: NERO, F. G. D. ; FRENEDOZO, R. C. Concepções dos discentes dos cursos de licenciatura sobre educação ambiental, sua responsabilidade 
social e o papel formativo da universidade. Encontro Nacional De Pesquisa em Educação em Ciências. Anais... Florianópolis, 2009. CD-ROM.

SMYTH, JC. Environmental education: a view of a changing scene. Environmental Education Research, vol. 1, n. 1,1995.

TRISTÃO, M. Espaços/tempos de formação em educação ambiental. In: GUERRA, A. F. S.; TAGLIEBER, J. E. Educação ambiental: fundamentos, práticas e desafios. Itajaí: Universidade do Vale do Itajaí, 2007. 